\title{
An Exploratory Study for Effective integration of ICT in Fashion Design Education of India: A Delphi approach
}

\author{
Suhail Anwar ${ }^{1}$, Dr. Sibichan K. Mathew ${ }^{2}$ \\ ${ }^{I}$ National institute of Fashion Technology, India \\ ${ }^{2}$ National institute of Fashion Technology, India
}

\begin{abstract}
Information and Communication Technology (ICT) pockets together many technologies - current and emerging -which enable users to receive and send information through signal detection and interpretation. In the realm of education, ICT contribution can be broadly categorized as a medium for corroboration, support for traditional subjects and as an administrative tool. To effect this contribution productively, implementation of ICT in form of tools and equipments turns mandatory. This research study explores the critical use of ICT in the field of fashion design and recommends ways to increase the factor of efficiency and effectiveness. This research provides direction for subsequent exploration, given that limited study that has been conducted in India. This study adopts the Delphi approach, which summarizes the opinion of experts through the process of thesis and anti-thesis till a synthesis is achieved and arrived at. It therefore provides a foundation for in-depth study in the area of ICT in Fashion Design Education from an Indian perspective.
\end{abstract}

Keywords: ICT, Fashion Design Education, Delphi

\section{INTRODUCTION}

The Information Paradigm was redefined not so long ago and since then jets of information have created a complex labyrinth that puzzles. With new and newer technologies getting wombed every other second, information has become a commodity that is so very easily accessible. Creating, storing, sharing or transmitting, exchanging information is now no bother unlike the dying decades of the last century. Technologies of the form that slave itself to newly defined information silhouette are called Information and Communication technologies (ICTs). Physicals such as radio, television, video, DVD, telephone (both fixed line and mobile phones), satellite systems, computer and network hardware and software ${ }^{1}$ form the basket. Equipment and services associated with these technologies such as video-conferencing and electronic mail add air to the basket.

To kin this study, ICTs would include all digital devices, tools, resources and services that can be called upon for realizing the goals of teaching - learning. The tentacles would hug the management of the education system as well. With ICT engulfing all spheres of life including education, it may be of interest to categorize education under four categories: e-learning, online distant education, tradition curriculum supplemented with technology and hybrid courses. With an embrace of this kind, education, it is widely believed will go under the knife for a transformation. The education system, static for these many years in approach will, now, be parloured into a modernized form : Teaching - learning would undergo a change. Numerous studies, outside the country in different streams, in the past have been undertaken to explain the role of ICT in education. The impact of the role of ICT has been recorded as one of performance improvement among the student community and effectiveness of teaching among the teaching community.

The researcher, in this study, parks himself in the realm of comfort by focussing on Fashion Design education, a field of familiarity and analyzes the impact and role of ICT in qualitative terms. The results drawn from this research may not necessarily be conclusive, but will provide a platform for further research. The qualitative terms, as defined earlier in the paragraph, would be arrived at through the approach of Delphi method where the opinion of experts in the discipline would be summarized to form a consensus.

\section{OBJECTIVES OF THE STUDY}

ICT has touched education in a golden way - to an extent where it is used for collaborative learning, distance education and academic administration. In disciplines where teaching - learning is process based, the use of ICT is yet to be explored to potential. This study is an attempt to dig further into the virgin territory and understand the major concerns thereof. In the process of this exploration, the researcher attempts to solder ICT into the learning process and understand its effectiveness. It will thereby lens through the factors that contribute towards the effective use of ICT in the stream of Fashion design from an Indian perspective. 


\section{REVIEW OF LITERATURE}

Colette Murphy \& Lillian Greenwood in their work on 'Effective Integration of Information and Communications Technology in Teacher Education' have, in the UK, worked on ways to make the new IT curriculum effective for teachers. Their work, it was noted, challenged the initial teacher training institutions. In their study, the researchers zeroed in on three factors that restricted the use of ICT's in establishments of learning. The three factors are as follows:

Students access to computers

The policy on ICT championed by the initial teachers

Lack of thrust for students to use ICT on teaching practice ${ }^{2}$.

In yet another study on the impact of ICT on education by A.K. Jager \& A.H. Lokman, Stoas Research in Wageningen, Netherland ${ }^{3}$. The researchers focussed on the role of teachers and Teacher training in the use of ICT and their effectiveness thereof. The paper concluded that ICT has not been accepted and embraced in Dutch vocational education to an extent where it can be labelled mature, though it identifies the fact that there are umpteen technical possibilities such as ICT as teaching aids, communication tool, documentation tool et al. While there have been attempts abroad on understanding the use of ICT in education, let us look at researches closer to home. In their study on 'Enhancing the Quality and Accessibility of Higher Education through the use of Information and Communication Technologies', Ashish Hattangdi and Prof. Atanu Ghosh ${ }^{4}$, spotlight their focus on the scope of ICT in the Indian education sector. The research diagnoses the problems the education sector faces in developing countries like India and suggest e- learning as a panacea to cement any gaps that exist. The researchers do bring to the level of consciousness the drawbacks and challenges of integrating ICT into the system of teaching methodology. While the study points to conducive national policies and school policies as a factor to successfully integrate ICT into the curricula, there are other factors too that cannot be ignored, the study concludes. The study recommends institutes create blueprint that supports and trains the various stakeholders in the integration of ICT. As an effective result of ICT, it was noted that such integration would benefit the student community in learning skills. The domino effect, the study concludes would contribute to the economy of the nation besides collaborative knowledge creation. It goes on to say that ICT, besides helping the teacher graduate to higher level of computer literacy, helps create a better linkage with the students too.

While the studies above focus on ICT on education, a project undertaken by Elaine Evans, University of Leeds, United Kingdom ${ }^{5}$, was specific to Fashion design. The project was to develop online learning support materials for a BA (Hons) Fashion Design programme. This was an ambitious attempt to explore ways to support practical demonstrations in virtual learning environment. The researchers, to begin with, investigated the learning methods in a process- based environment and concluded that, in such process based environment, the experience of virtual learning has clear advantages over conventional learning methods.

Focussing on Fashion education, Lena Berglin, Sara Lotta Cederwall, Lars Hallnäs, Birgitta Jönsson, Anne Karine Kvaal, Lotta Lundstedt, Maria Nordström, Barbro Peterson, Clemens Thornquist worked on 'Interaction Design Methods in Fashion Design Teaching' with the objective of introducing interaction design methods in fashion design teaching to make act design explicit throughout the different stages of the design process in a organized manner. It also highlighted a general workshop curriculum in experimental fashion design focusing on the articulacy of wearing and use. A series of test workshops were conducted to provide a foundation for manifestation and discussions. The main results stimulated by workshop evaluations, consisted of theoretical models for a systematic development of workshop exercises in fashion design aesthetics ${ }^{6}$.

In an study conducted in china by Qing Zhou A, Yingmin Zhao a, Jiani Hu a, Yang Liu a, Lijuan Xing on 'Pre Service Chemistry Teachers' attitude toward ICT in Xi'an"7 , the respondents acknowledge the fact that ICT is a viable educational tool with the potential of changing the education teaching landscape through radical improvements in teaching methodology. The study also finds the attitude of teachers towards ICT to be positive and the justification for ICT introduction well received.

While there are umpteen researches that have been conducted in the past, the ROL touches upon a miniscule .It may be said, from the researches of the past and present that ICT as a tool has been acknowledged as a game changer and not embracing it would leave an institute out of the race. 


\section{RESEARCH DESIGN}

The Research study has adopted the Delphi method, having used an exploratory design. The results, it may be made known, is qualitative in nature. Delphi method demanded a panel of experts and the same were chosen from the academia and the industry. The modus operandi was as follows: Emails were shot out to the panellist for their opinions on the subject matter that was capsuled as a questionnaire. The opinions were studied and another round of opinion sharing was conducted. Likewise three rounds were undertaken prior to freezing on the conclusions. It may be of interest to bring it one's notice that the panellists were anonymous and unknown to one another. This confidentiality created a power balance and eliminated the influence one could have over another. on a secondary note, email was the method of adoption to avoid the problem of time and place inconvenience to the panellists.

Dwelling on the Delphi approach, the questionnaire, an open ended one, was distributed amongst the panellists for their opinions. This was the round one and analysis of responses to the questionnaire helped develop a master list of fourteen suggestions. In subsequent rounds of two and three, the panellists were supplied the master lists and were asked to review their opinion from the previous round. The responses were further studied by the researcher and in the final analysis four distant points emerged. This result was used as the springboard for subsequent quantitative research.

\subsection{Delphi Method}

The genesis of the Delphi method can be traced to RAND Corporation in Santa Monica, California. It was first developed in circa 1950. The Delphi approach consists of 2 or more rounds of survey. The participants are, in rounds beyond the first, given an opportunity to review their opinions from the first or previous rounds based on receipt of new information received. This helps in "opinion strengthening" and a more productive use of group interaction ( Rowe et al. 1991, Häder/Häder 1995) ${ }^{8}$. The Delphi approach protects the identity of the respondent too. The initial contributions from the experts are collected in the form of answers to questionnaires and their comments to these answers. The number of rounds is decided on the reach of consensus, failing which the process continues through thesis and anti-thesis to gradually work towards synthesis.

The role of the researcher is to control interactions among the respondents by playing the role of information gate keeper where information hoarding is discouraged and irrelevant content filtered.

\section{METHODOLOGY OF THE PRESENT STUDY}

The Delphi panellist constituted a group of experts in Fashion Design and / or ICT, and the current study has drawn its data from these expert panellists. Each panellist was unaware of the other and this gives reason to believe that the responses were authentic, original and devoid of any influence by other panel members. The process took three months to arrive at a conclusion, the details of which are presented below:

Round One: In this round, there were eight panellists. Each of the panellists was supplied objective questions framed with a combination of ranking and rating scales. The objective was to understand the broad view of the panellists. The questionnaire, as explained earlier, was mailed to the panellists and responses received likewise. The analysis of the data received in this round pointed to a unanimous agreement on the favourability of ICT. The panellists also agreed on the difficulty in implementing ICTs. Based on these unanimous agreements, the following emerged:

- Integration of ICT in the Teaching pedagogy- How?

- Important consideration in ICT implementation - what?

The subsequent rounds mazed through the above two questions.

Round Two: While round one was objective in nature, the subsequent round two focussed on the key derivatives of round one. The responses received from the panellist were mixed. Based on the responses received, a master list of fourteen suggestions was developed. This was used as the basis for round three. Below printed is a gist of the responses received from the panellists:

- Faculty training and infrastructure improvement are factors of focus for effective use of ICT. Besides, inclusion of online research sites like stylesight.

- Appropriate ICT support with interactivity to be developed.

- Dissemination of information about usage required for faculty. 
- The application of ICT in areas like illustrations, print development, pattern making, portfolio development etc. would provide students and teachers a wider canvas to work on.

- All rounds up-gradation of infrastructure across institute and industry.

- Software availability, faculty education, and faculty interaction with industry are the identified major factors for successful integration of ICT in Fashion Design education.

- Encouraging the use of ICT tools in the students learning process.

- Enhancement of effectiveness of the current curriculum by incorporating an ICT perspective.

- Undergraduate students need the opportunity to discuss, evaluate, interpret and comprehend the new content including ICT.

- Understanding the relevance of ICT in an institutional context.

- Success of ICT depends on teachers' pedagogical beliefs and their perceived notion about ICT.

- Due deliberation on ICT driven curriculum strategies and their relation to the different modes of teaching and learning.

- The use of ICT to be highly encouraged in routine pedagogical tools and techniques.

- The use of ICT as an essential complimentary tool in certain subject to be encouraged, though guard must be taken against a total replacement.

Round Three: In the round three, the panellists were asked to review the master list from the previous two rounds. An opinion review was sought, if there be any. $80 \%$ of the panellist arrived at a broad consensus which culminated in eight points. They are as follows:

- ICT has a positive impact on learning and performance. Empirical belief revolves around ICT playing quiet a significant role in improving the performance of the students in the fashion design discipline.

- It was agreed upon by the panellist that there is a severe lack of ICT awareness amongst the faulty community on the benefits of ICT.

- The ICT impact varies amongst courses and streams.

- ICT may not be preferable for select courses.

- Curriculum should carry extensive notes of ICT involvement.

- Primary reasons for under utilization of ICT may be attributed to lack of adequate infrastructure, lack of competency among faculty and lack of systems or policies for ICT implementation.

- The benefits, it was agreed, could be better accrued if teaching pedagogy includes adequate ICT.

- ICT must be made part of pedagogy for substantive impact.

The above eight outcomes were consolidated to derive the following distinct points

- ICT positively impacts performance though the effect may be subjected specific.

- Major stake holders are less informed about the benefits of ICT.

- The primary reasons for its under utilization could be:

1. Lack of adequate Infrastructure

2. Poor ICT competence of faculty members

3. Lack of proper system for implementation

- The pedagogy demands precise articulation of ICT involvement.

\section{CONCLUSION}

The final outcomes were reviewed in the light of the main issues of research. The research begins with the identification of ICT integration which demands a review of pedagogy vis-à-vis ICT infrastructure for each subject. It necessitates a thorough investigation of the courses, program goals and available infrastructure to develop a suitable framework for effective ICT use. The successful integration of ICT in Fashion Design education relies on the perception of stakeholders - faculty members and students. It can be concluded that ICT affects the quality of education by improved learning, albeit course-specific. It is recommended that a conclusive research be undertaken to substantiate the Delphi results.

\section{REFERENCES}

[1] United Nations Educational, Scientific and Cultural Organization (UNESCO) Bangkok: Using ICT to Develop Literacy,2006

[2] Colette Murphy \& Lillian Greenwood, Effective integration of information and communications technology in teacher education, Journal of Information Technology for Teacher Education, 1998

[3] A.K. Jager \& A.H. Lokman, Impacts of ICT in Education. The role of the Teacher and Teacher Training. European Conference on Educational Research, Lahti, Finland,1999 
[4] Ashish Hattangdi and Prof. Atanu Ghosh, Enhancing the quality and accessibility of higher education through the use of Information and Communication Technologies, 11th Annual Convention of the Strategic Management Forum (SMF), 2008

[5] Elaine Evans, Looking to the future; a response to the challenges of design education in the 21st Century using C\&IT,2010

[6] Lena Berglin, Sara Lotta Cederwall, Lars Hallnäs, Birgitta Jönsson, Anne Karine Kvaal, Lotta Lundstedt, Maria Nordström, Barbro Peterson, Clemens Thornquist. Interaction Design Methods in Fashion Design Teaching, The Swedish School of Textiles University College of Borås, 2008

[7] Qing Zhou a, Yingmin Zhao a, Jiani Hu a, Yang Liu a and Lijuan Xing a., Pre-service chemistry teachers' attitude toward ICT in Xi'an, Elsevier Ltd.,2010

[8] Gene Rowe, George Wright, A Delphi Technique as a forecasting tool: Issues and Analysis, Elsevier International Journal of forecasting 15(1999) 353-375, 1999 